\title{
miR-944 Suppresses EGF-Induced EMT in Colorectal Cancer Cells by Directly Targeting GATA6
}

This article was published in the following Dove Press journal: OncoTargets and Therapy

\author{
JingTong Tang' \\ Wei Gao' \\ Gang Liu' \\ WeiWei Sheng' \\ JianPing Zhou (D) \\ Qi Dong ${ }^{2}$ \\ Ming Dong $\mathbb{D}^{\prime}$ \\ 'Department of Gastrointestinal Surgery \\ \& Hernia and Abdominal Wall Surgery, \\ The First Hospital, China Medical \\ University, Shenyang, II000I, Liaoning, \\ People's Republic of China; ${ }^{2}$ Department \\ of General Surgery, The People's Hospital \\ of China Medical University, Shenyang, \\ People's Republic of China
}

Background: miR-944 belongs to the MicroRNAs family, as shown in our previous study, and is essential in the colorectal cancer (CRC) progression. It is negatively associated with invasion depth and lymph node status. Epithelial-mesenchymal transition (EMT) is essential in tumor invasion and metastasis. However, the relationship between miR-944 and EMT in CRC is unknown and should be further investigated.

Methods: Epithelial-mesenchymal transition (EMT) progression in CRC cell lines was detected with Cell morphology and Western blotting. CRC cell migration and invasion were examined using Transwell assays. Transcriptome and clinical data were obtained from The Cancer Genome Atlas (TCGA) database. The potential pathway of miR-944 and GATA6 were predicted using KEGG analysis. Colocalization was validated using immunofluorescence and Immunohistochemistry. Nuclear and Cytoplasmic Protein Extraction assays were conducted to determine the effects of miR-944 on Wnt/ $\beta$-catenin signaling.

Results: We found that miR-944 influences EGF-induced EMT malignant phenotype in vitro. KEGG analyses showed that miR-944 and GATA6 are associated with EMT related pathways, wnt signaling pathways. On the other hand, Western Blot analyses showed that miR-944 can regulate EMT and wnt- $\beta$-catenin pathway-related protein, including $\beta$-catenin, ZEB1, snail1 via GATA6 regulation. miR-944 also abrogates E-ca after EGF induction. Immunohistochemistry (IHC) and Immunofluorescence (IF) co-expression showed that GATA6 expression is positively associated with $\beta$-catenin and ZEB1. GATA6 silencing can reverse EMT malignant phenotype and alterations of related protein induced by miR- 944 . Quantitative polymerase chain reaction analysis results showed that miR-944 is negatively associated with the UICC stage $(\mathrm{P}=0.02)$, lymph nodes $(\mathrm{p}=0.04)$, and liver metastasis $(p=0.03)$. Moreover, patients with high miR-944 expression have better survival $(p=0.045)$. We finally combined miR-944 and GATA6 and found that miR-944/GATA6 ratio could be a novel prognostic biomarker in the TCGA dataset and it is an independent risk prognosis factor $(\mathrm{p}=0.045)$.

Conclusion: Our results suggest that miR-944 suppresses the aggressive biological processes by directly repressing GATA6 expression and could be a potential candidate for therapeutic applications in CRC.

Keywords: miR-944, colorectal cancer, GATA6, epithelial-mesenchymal transition

\section{Introduction}

Colorectal cancer (CRC) ranks third in cancer incidence rates and is the world's second cause of cancer-related deaths. ${ }^{1,2}$ About $25 \%$ of CRC patients
Correspondence: JianPing Zhou

Fax +86 24-83282886

Email zjphama@I63.com
OncoTargets and Therapy 2021:14 23II-2325

2311

DovePress if in $>$

http://doi.org/10.214710TT $\$ 290567$ 
experience metastasis either at the time of diagnosis or recurrence and most CRC patients with distant metastasis had a poor 5-year survival rate $(15 \%){ }^{3}$ It is therefore important to understand the underlying metastases biological mechanisms of CRC and establish a novel therapeutic target that can help in the CRC malignant process.

The "epithelial-mesenchymal transition" (EMT) (major developmental regulatory program) is essential in promoting tumor invasion and metastasis in colorectal cancer. ${ }^{4}$ Neoadjuvant therapy can suppress or reverse CRC processes to reduce metastases, recurrence, and resistance. ${ }^{5,6}$ It is important to find key target playing a significant role in EMT progression for CRC treatment.

GATA6 belongs to the GATA family of transcription factors that binds to the A/TGATAA/G sequence and enhance or suppress downstream gene expression. ${ }^{7}$ GATA6 is located in the human chromosome (18q11.2) and plays various roles in cancer development. ${ }^{8,9}$ miR-944 is a conserved miRNA located in the human chromosome (3q28) and it inhibits several cancer cells' migration and invasion. ${ }^{10,11}$ Our previous study found that miR-944 inhibits Colorectal cancer (CRC) development by targeting GATA bind protein 6. miR-944 is also negatively associated with CRC patients' (TNM) stage, invasion depth, and lymph node status. ${ }^{12}$

This study aimed to determine the miR-944 mechanism on the biological regulation of the EMT process in CRC. We first found that miR-944 suppresses malignant EMT biological behavior in CRC cells and is also negatively associated with CRC patients' (TNM) stage, lymph node status, and liver distance. CRC patients with low miR-944 expression have poor survival. Furthermore, we confirmed that GATA6 as miR-944 target gene can regulate $\mathrm{Wnt}-\beta$-catenin pathway, consistent with the KEGG analysis. We finally demonstrated that the low miR-944/GATA6 ratio is associated with poor survival in CRC patients. In conclusion, miR-944 suppresses the biological processes and could be a potential exogenous biological reagent for the $\mathrm{CRC}$ therapy.

\section{Materials and Methods}

\section{Human Tissue Specimens and Cell Lines}

We collected 140 pairs (67 men and 73 women median age of 61.7 years and age range of 29-81 years) of fresh colorectal cancer and their paired adjacent non-tumor colorectal tissues after colorectal cancer surgery at the Gastrointestinal Surgery Department of the First Affiliated Hospital of China Medical University. All the specimens were pathologically diagnosed as colorectal cancer, and the data was classified following the 8th UICC guideline. Informed consent was obtained from some patients, and the remainder were exempt from informed consent as anonymity was assured, as approved by the ethics committee of the First Affiliated Hospital of China Medical University. This study was conducted in accordance with the Declaration of Helsinki. miRNA and mRNA expression data (except a too high or too low expression of miR-944 and GATA6) and the clinicopathological annotations of $285 \mathrm{CRC}$ patients were downloaded from the TCGA portal (http://cancergenome.nih.gov). We analyzed the correlation between GATA6 and $\beta$-catenin, $\beta$-catenin, and ZEB1 using GEPIA. ${ }^{13}$

Two CRC cell lines (HCT116 and SW480) were sourced from a cell bank at the Chinese Academy of Sciences (Shanghai, China) and cultured with a recommended growth medium supplemented with $10 \%$ fetal bovine serum (FBS; Hyclone, Logan, UT, USA) and $100 \mathrm{U} / \mathrm{m}$ penicillin or streptomycin in a humidified chamber with $5 \% \mathrm{CO} 2$ at $37^{\circ} \mathrm{C}$.

\section{Kyoto Encyclopedia of Genes and} Genomes (KEGG) Analysis and Gene Set Enrichment Analysis (GSEA)

We classified the samples into high-expression and lowexpression miR-944 groups according to the miR-944 expression median levels and conducted KEGG analysis using GSEA. miR-944/GATA6 ratio was also used to conduct a similar analysis.

\section{RNA Isolation and Quantitative Real-Time PCR}

We extracted Total RNA from CRC cell lines and colorectal tissue and stored them in liquid nitrogen with Trizol reagent (Takara Bio, Otsu, Japan) according to the instructions. NanoDrop ND-1000 instrument (NanoDrop, USA) was used to measure miR-944, and Hairpin-it microRNA concentration and RT-PCR Quantitation Kit (Shanghai, China) was used to normalize U6 snRNA. We used Cycle Dice RealTime (Thermal) to measure miRNA expression levels according to instructions with U6 RNA as the internal control. Thermocycling conditions were: $95^{\circ} \mathrm{C}$ for $3 \mathrm{~min}$, then 45 cycles of $95^{\circ} \mathrm{C}$ for $12 \mathrm{~s}$, and $62^{\circ} \mathrm{C}$ for $45 \mathrm{~s}$. The following primers were used: miR-944 forward primer, 5'-GCACTCCTAAAATTATTGTACATCG-3'; U6 forward primer, 5'-CTCGCTTCGGCAGCACA-3'; miR-1 reverse primer, 5'-TATGGTTGTTCACGACTCCTTCAC-3', U6 reverse primer, 5'-AAC GCTTCACGAATTTGCGT-3. The 
relative f miR-944 expression was represented as Fold changes $\left(2^{-\Delta \Delta \mathrm{Ct}}\right)$ and each experiment was conducted thrice in replicate.

\section{Protein Isolation and Western Blot}

RIPA lysis buffer containing 1\% PMSF was used to extract the Total sample from two infected CRC cell lines (HCT116 and SW480). We separated protein samples using 10\% sodium dodecyl sulfate-polyacrylamide gel and then transferred them on PVDF membranes. The membranes were enclosed with 5\% non-fat milk for 2 hours and incubated with a rabbit anti-GATA6 antibody at 1:500 dilution (CST, USA), a rabbit anti- $\beta$-catenin antibody 1:1000 dilution (Proteintech, USA), a rabbit anti-ZEB1 (Proteintech, USA) at 1:1000 dilution, a rabbit antiLamin B1 (Beyotime, China) at 1:1000 dilution, a mouse anti-GAPDH (Proteintech, USA) at 1:3000 dilution at $4^{\circ} \mathrm{C}$ for $12 \mathrm{~h}$. The secondary antibodies were used correspondingly for 2 hours. We assessed the Western blot results using the ECL detection kit (Thermo Scientific, Rockford, IL, USA) and each experiment was done thrice.

\section{Immunoprecipitation}

Lysis buffer contained $20 \mathrm{mM}$ Tris/ $\mathrm{HCl}$ (pH7.4), 1.0\% NP40, $150 \mathrm{mM} \mathrm{NaCl}, 1 \mathrm{mM}$ EDTA, $10 \mu \mathrm{g} / \mathrm{mL}$ leupeptin, and 50 $\mu \mathrm{g} / \mathrm{mL}$ PMSF. We used lysis buffer to extract CRC cell protein. Preincubated antibody-beads with magnetic beads (Bio-Rad, Hercules, CA, USA) and 200ul rabbit GATA6antibody (CST, USA) or IgG (Santa Cruz, Japan) at 1:100 dilution were incubated with extracted CRC protein at $4{ }^{\circ} \mathrm{C}$ overnight. We used Western blot the following day to visualize immunoprecipitation sample separated using magnetic beads. We used RIPA lysis to wash immunocomplex.

\section{Immunohistochemistry (IHC)}

We deparaffinized Paraffin-embedded PC tissues continuous sections (4um) at $65^{\circ} \mathrm{C}$ for $2 \mathrm{~h}$ and then washed them using ethanol and xylene. Antigen repair was done at high pressure for $2.5 \mathrm{~min}$ for GATA6, $\beta$-catenin, and ZEB1. We then incubated sections with hydrogen peroxide (3\%) and $10 \%$ normal goat serum for $15 \mathrm{~min}$ and $20 \mathrm{~min}$, respectively. The sections were also incubated with a GATA6 antibody (1:200) (CST, USA), $\beta$-catenin antibody (1:200) (Proteintech, USA) and ZEB1 (1:200) (Proteintech, USA) at $4{ }^{\circ} \mathrm{C}$ overnight. We incubated secondary antibody using streptavidin-peroxidase reagent with sections for $15 \mathrm{~min}$, and then added 3,3'-diaminobenzidine (DAB) for color reactions and visualized at $\times 20$ magnification.
We conducted Immunohistochemistry (IHC) score as previously described. ${ }^{14}$ GATA6, $\beta$-catenin and ZEB1 coloration ranges were used as the standard to assess the staining score defined as 1 (0-25\%), 2 (25-50\%), 3 (50-75\%), 4 (75-100\%) [0 (negative), 1 (weak), 2 (moderate) and 3 (strong)]. The two scores were the final score ranging between 0 to 7 , and the final score $\geq 3$ was defined as positive expression.

\section{Transfection}

We synthesized miR-944 mimics, miR-944 inhibitor, and GATA6 siRNA and their corresponding negative control (NC) at GenePharma (Shanghai, China) and the sequence were; miR-944 mimics, 5'-AAAUUAUUGUACAUCG GAUGAG-3', Negative control, 5'-UUCUCCG AACGUG UCACGUTT-3', miR-944 inhibitor, 5'-CUCAUCCGAUGU ACAAUAAUUU-3', MircoRNA inhibitor N.C, 5'-CAG UACUUUUGUGUAGUACAA-3'. We used Lipofectamine 3000 (Invitrogen, Carlsbad, CA, USA) to perform transfection according to the manufacturer's instructions. The transfection efficiency had been tested in our previous study.

\section{EMT Construction}

We incubated miR-944 mimics, miR-944 inhibitor, and miR-944 inhibitor + GATA6 siRNA, and their corresponding scramble infected two CRC cell lines (HCT116 and SW480 cells) with 50 ng/mL EGF (Peprotech, RockyHill, NJ, USA) twice for 48 hours using 1\% BSA (Sigma) as a control. Cells were cultured with the recommended growth media containing 1\% FBS to enhance the EGF effect. We observed EMT-like cell morphology (a spindleshaped and fibroblast-like morphology), EMT-induced cell invasion and migration, and the alteration of the EMTrelated protein, verifying the EMT process.

\section{Cell Migration and Invasion Assay}

We constructed miR-944 overexpression, HCT116 downregulation, and SW480 cell lines as previously described. We added $8 * 104$ infected HCT116/well and $5 * 105$ infected SW480/well in 300ul free medium into the upper chamber and $600 \mu \mathrm{L}$ medium with $10 \%$ fetal bovine serum into the bottom chamber. We coagulated the upper membrane with Matrigel (BD Biosciences) for invasion assays. PC cells stuck in the bottom membrane were stained after 24 hours using cool methanol and dried using $0.1 \%$ crystal violet (Sigma) for $30 \mathrm{~min}$. We used a microscope (Nikon Microphot-FX, Tokyo, Japan) to take Cell photographs, and counted the number in five random fields per chamber at $\times 20$ magnification. 


\section{Immunofluorescence (IF)}

Briefly, we fixed CRC cells plated in 24-well culture plates using $4 \%$ paraformaldehyde at room temperature for $30 \mathrm{~min}$. The samples were then permeabilized in $1 \%$ Triton X-100 and blocked in 5\% BSA for $2 \mathrm{~h}$ and then incubated with primary antibody [rabbit anti-GATA6 at 1:100 dilution (CST, USA) and mouse anti- $\beta$-catenin at 1:100 dilution (Proteintech, USA)] at $4{ }^{\circ} \mathrm{C}$ overnight. The secondary antibodies were then incubated with green FITC (Proteintech) and red TRIC (Proteintech). We finally co-stained the cells using DAPI (Sigma, St. Louis, MO, USA) for nuclei visualization and used a fluorescence microscope (Nikon Microphot-FX, Tokyo, Japan) for visualization.

\section{Statistical Analysis}

The three independent experiments results were represented as the mean \pm standard deviation and we used SPSS 17.0 statistical software (Chicago, IL, USA) to conduct all the statistical analyses. Scientific graphing was plotted using GraphPad Prism (GraphPad Software, USA). Student's $t$-test was used to determine the relationship between miR-944 expression, clinicopathological parameters, and cell migration invasion assays. We used Chi-squared, and Cox's proportional hazards regression model for conducting univariate association analysis between clinicopathological factors and survival to determine independent prognostic factors. Pearson's correlation coefficient was used to explore the relationship between GATA6 and $\beta$-catenin or ZEB1. Protein GATA6, $\beta$ catenin, ZEB1, snail1, GATA3, E-cadherin, ZO1 expression results were analyzed using paired t-tests. $\mathrm{P}<0.05$ was considered as a statistically significant difference.

\section{Results}

miR-944 Ectopic Expression Affects EGFInduced EMT-Like Cell Morphology, and EGF-Induces Cell Malignant Invasion, Migration, and Intracellular Calcium Alteration in Two CRC Cell Lines

Several studies have found that EGF can induce cell EMT phenotype in various cancers and EMT is essential in cancer metastasis. ${ }^{15,16}$ We compared the cell morphology between miR-NC and miR-944 groups, anti-NC and anti944 groups, and the corresponding groups induced by EGF for two days. We found that both HCT116 and SW480 cells exhibited EMT-like cell morphology after EGF introduction and most cells lost their epithelial characteristics and had a spindle-shaped and fibroblast-like morphology. There was no significant cell morphology difference between the miR-NC and miR-944 groups, anti$\mathrm{NC}$, and anti-944 groups. We found that miR-944 exhibited EMT-like cell morphology and anti-944 had the reverse function after EGF introduction (Figure 1). We compared negative control and transfected groups to determine cancer cell invasion and migration assays. We found HCT 116 and SW480 cell invasion and migration in the miR-944 group with or without EGF treatment (Figure 2). On the contrary, the anti-miR-944 group with or without EGF treatment exhibited different results (Figure 2).

\section{miR-944 Suppresses EMT Activation via the Wnt- $\beta$-Catenin Signaling Pathway}

We first conducted KEGG analysis and found that GATA6 was all associated with the Wnt- $\beta$-catenin signaling pathway. (Figure 3A, Supplementary Table 1). Wnt- $\beta$-catenin signaling pathway is essential in the cancer EMT process. ${ }^{17}$ Hwang et $\mathrm{al}^{18}$ found that GATA6 directly affects Wnt6, leading to cellular $\beta$-catenin accumulation and canonical WNT- $\beta$ catenin pathway activation. We identified that miR-944 could bind to the 3'UTR of GATA6 in our previous study and hypothesized that miR-944 regulates the wnt- $\beta$-catenin signaling pathway. We then extracted protein from transfected HCT116 and SW480 cells to perform Western blot. The results showed that miR-944 overexpression significantly inhibited GATA6, $\beta$-catenin protein and ZEB1 (downstream protein of wnt- $\beta$-catenin signaling pathway) and EMT related protein (E-cadherin and snaill) expression in two CRC cells (Figure 3B and D), and also the $\beta$-catenin nuclear translocation (Figure $3 \mathrm{C}$ and E). We also found that GATA6 were co-stained in normal HCT116 and SW480 cells in the cytoplasm using IF (Figure 4A) and co-expression relationship between miR-944, GATA6, $\beta$-catenin, and ZEB1 using immunohistochemistry. (Figure 4B) Spearman's rank correlation was used to analyze the results and found consistency with Western Blot results (Table 1). We further identified that GATA6 was structurally binds to $\beta$-catenin in two colon cancer cells using IP analysis (Figure 4C). Moreover, the Correlation Analysis showed that GATA6 is positively associated with $\beta$-catenin while $\beta$-catenin is associated with ZEB1 in GEPIA (Figure 4D).

The intracellular calcium is essential for cellular function regulation, including gene transcription, cell proliferation, invasion, and migration. ${ }^{19,20}$ We used Fluo-4 and 

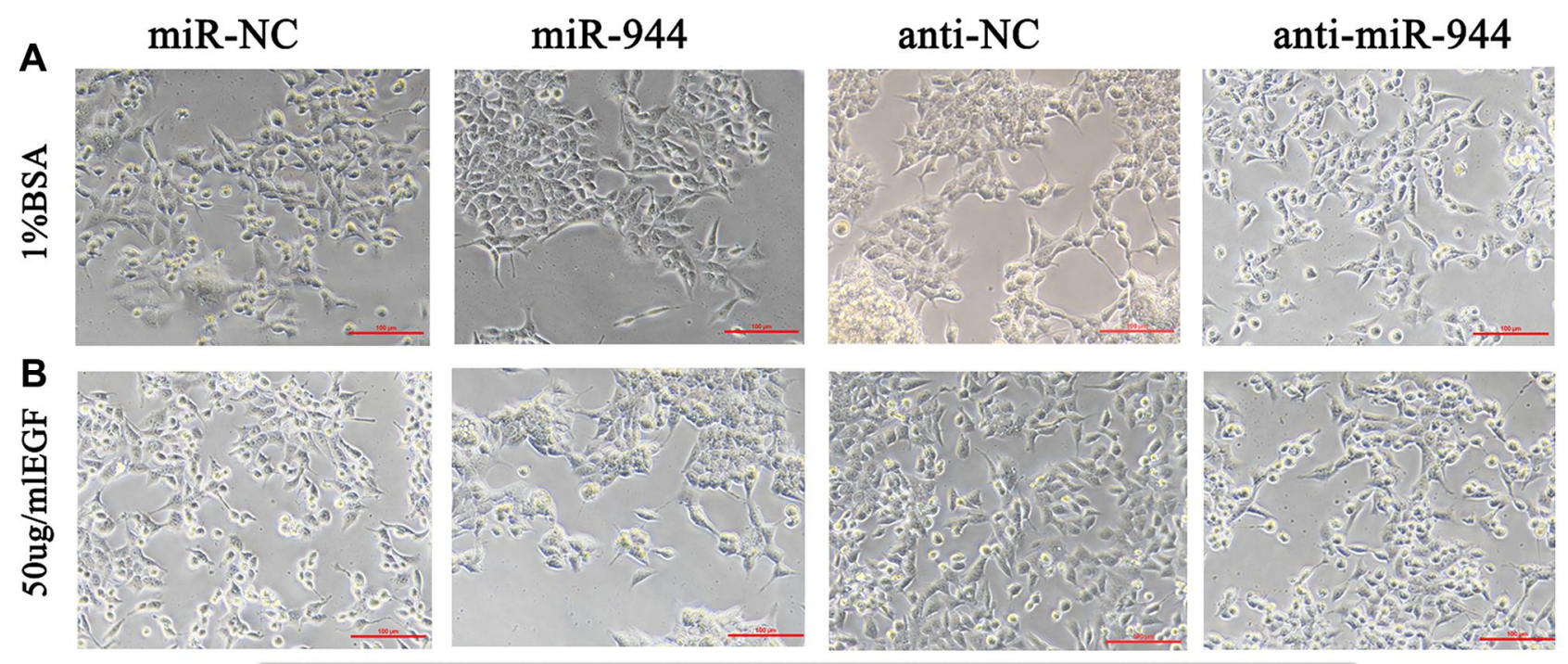

HCT116
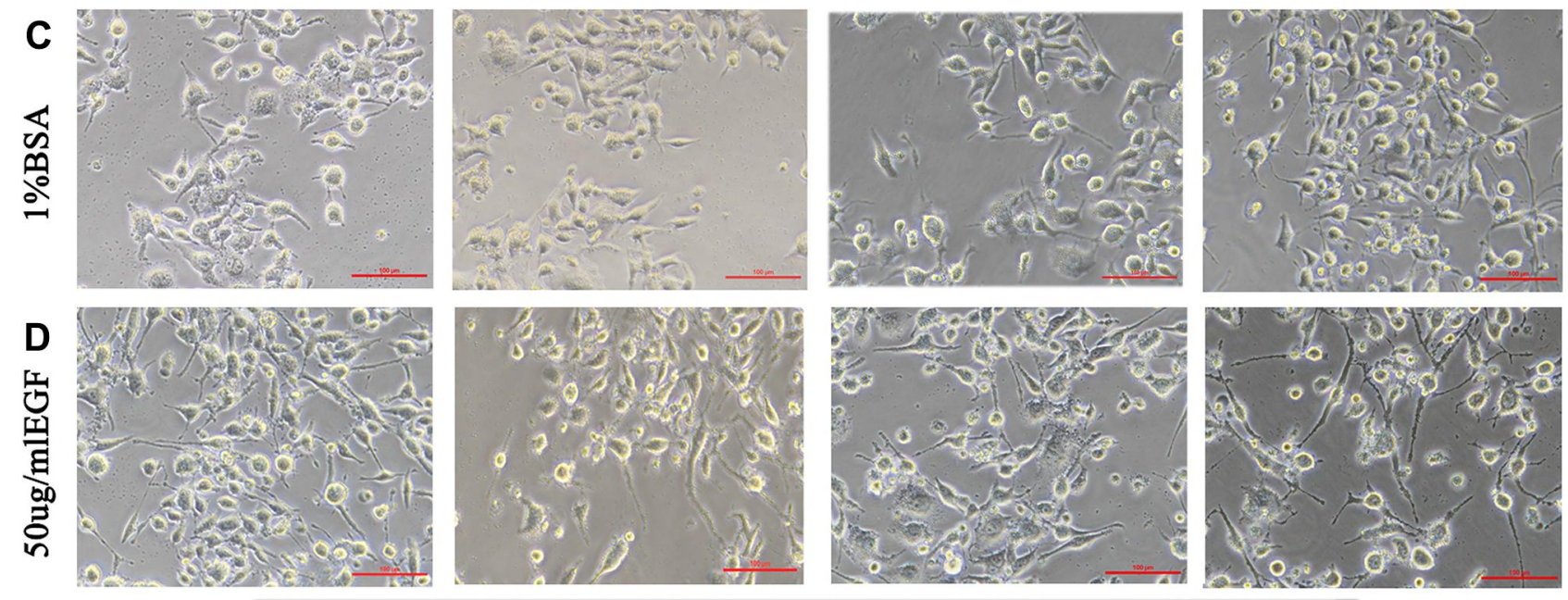

SW480

Figure I Cell morphology in miR-944, anti-miR-944, and corresponding negative control infected HCTII6 and SW480 cells with or without EGF (50 ng/mL) treatment. (A and C) BSA treatment, (B and D) EGF treatment. The fibroblastoid-like phenotype in HCTII6 (A and B) and SW480 (C and D) weakened miR-944 group cells compared with the scramble group. Anti-miR-944 had the opposite effect.

Fluorescence microscope to examine the intracellular calcium. $^{21,22}$ The Fluorescence intensity in the miR-944 group was weaker than in the miR-NC group. The anti-miR -944 enhanced intracellular calcium in HCT116 and SW480 (Supplementary Figure 1) and EGF-induced EMT was found to be calcium-signal dependent. ${ }^{23}$ Therefore, miR-944 can regulate CRC EMT phenotype by regulating intracellular calcium translocation.

In summary, miR-944 modulates EMT progress via GATA6-mediated Wnt- $\beta$-catenin signaling pathway regulation. (Figure 4E) by
GATA6 Silencing Reverses the AntimiR-944 Effects in Both CRC Cell Lines and miR-944 Can Suppress CRC EMT by Binding to GATA6

We conducted a rescue experiment and constructed three co-infected groups (anti-NC and siRNA-NC infected group, anti-miR-944 and siRNA-NC infected group, and anti-miR-944 and GATA6 siRNA infected group) and then compared CRC cell migration and invasion function and measured GATA6, $\beta$-catenin, and ZEB1 expression in the 
A

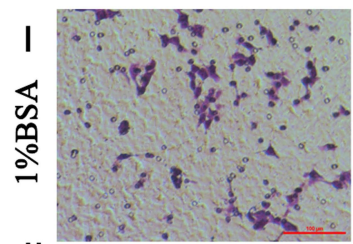

II $2 k^{2} \cdot \mathrm{x}^{2+3}+$
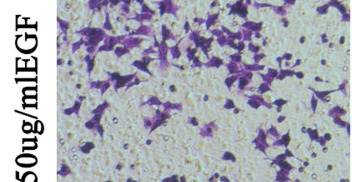

官

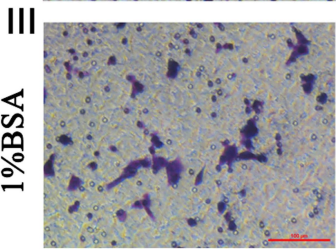

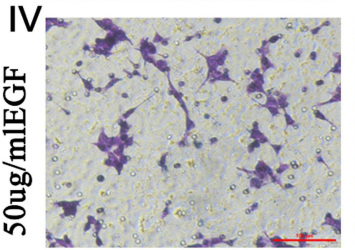

B $\quad$ miR-NC

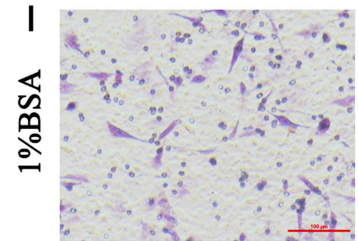

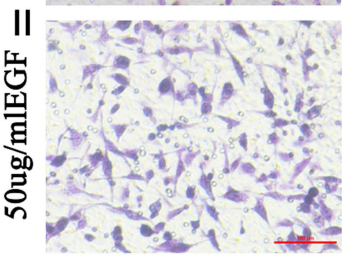
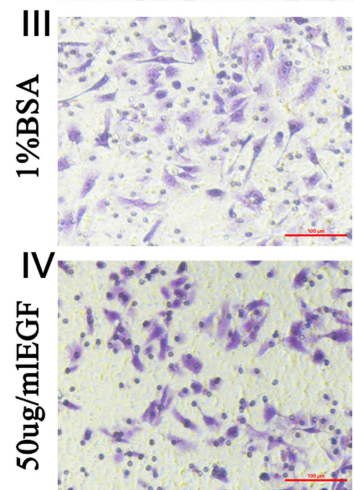

miR-944
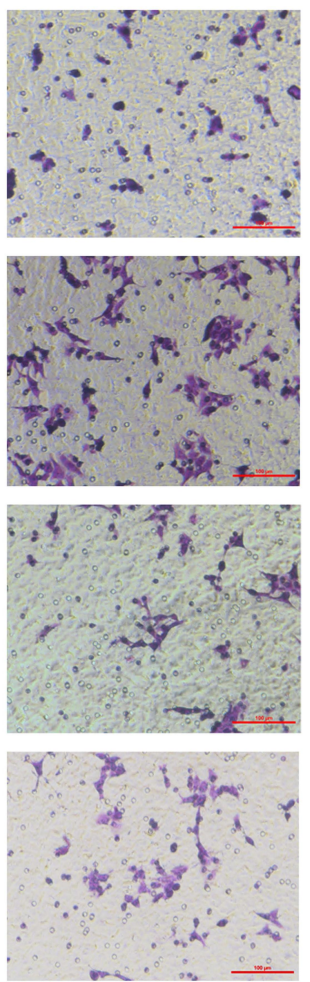

miR-944
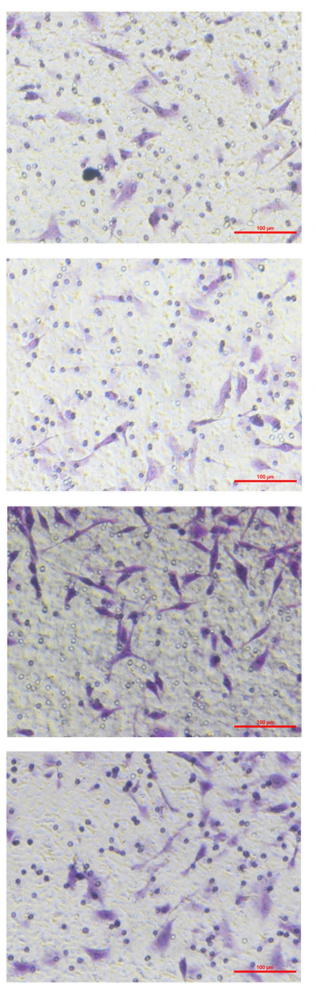

anti-NC
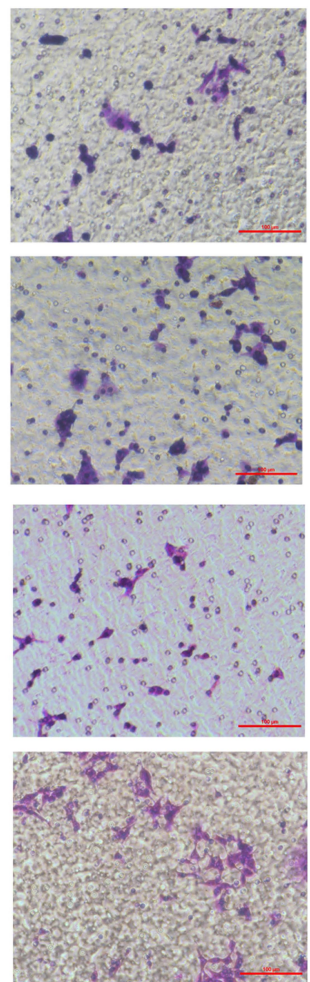

anti-NC

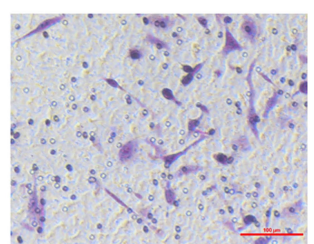

\section{anti-miR-944}
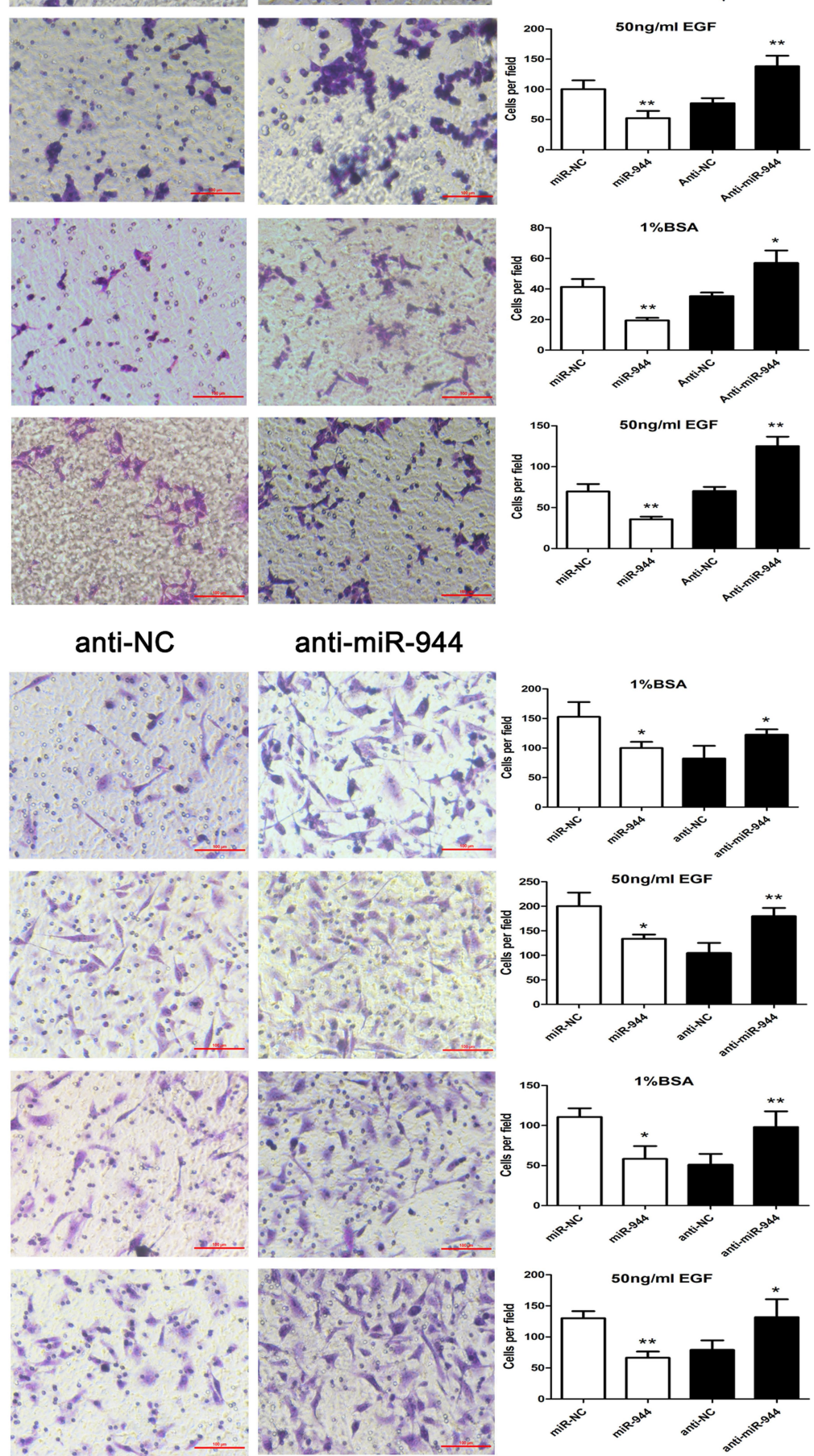

Figure 2 Cell invasion and migration in miR-944, anti-miR-944, and scramble-infected CRC cells with or without EGF treatment. Cell migration (Al and All) and invasion (AIII and AIV) in miR-944 and anti-miR-944 and scramble infected HCTII6 cells with or without EGF (50 ng/mL) treatment. Cell migration (BI and BII) and invasion (BIII and BIV) in miR-944 and anti-miR-944 and scramble-infected SW480 cells with or without EGF (50 ng/mL) treatment. White bars represent cell invasion or migration in the scramble and miR-944 groups with or without EGF treatment. Black bars represent cell invasion or migration in the scramble and anti-miR-944 groups with or without EGF treatment. Bars indicate \pm S.E. *P $<0.05$; **P $<0.01$ compared with control. 
A
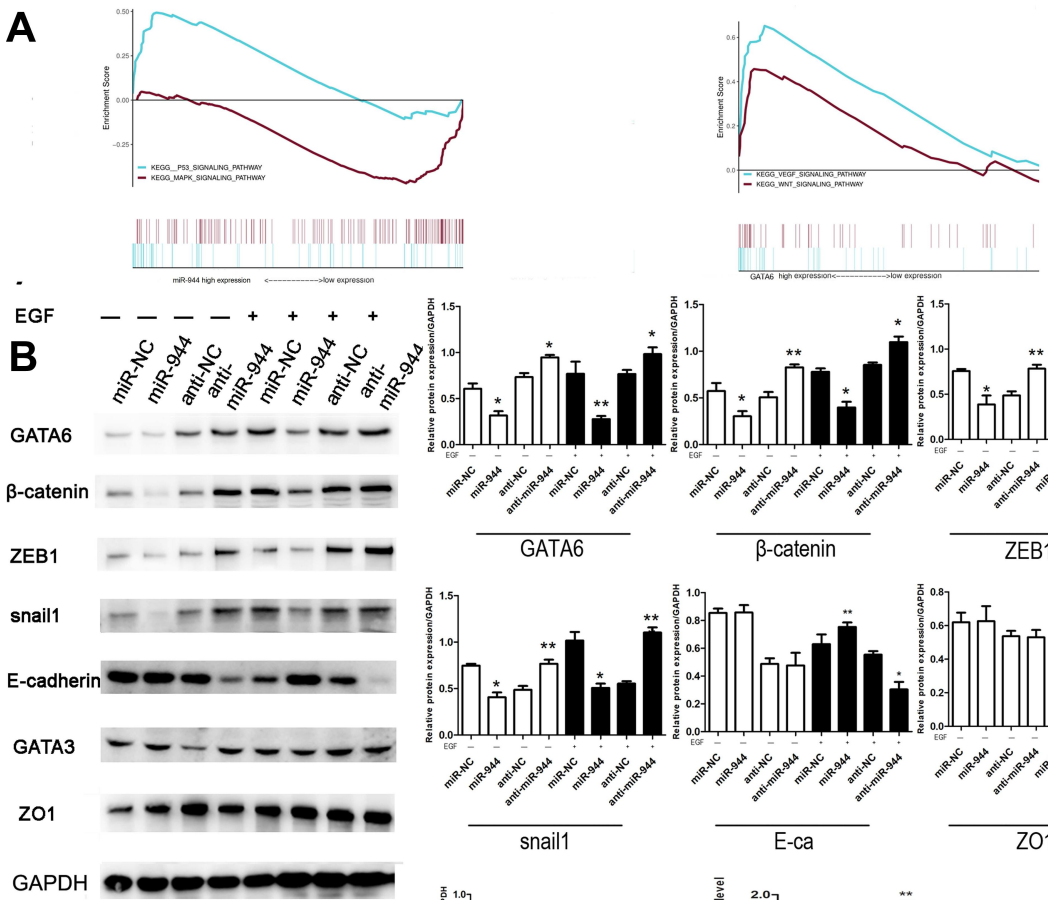

C
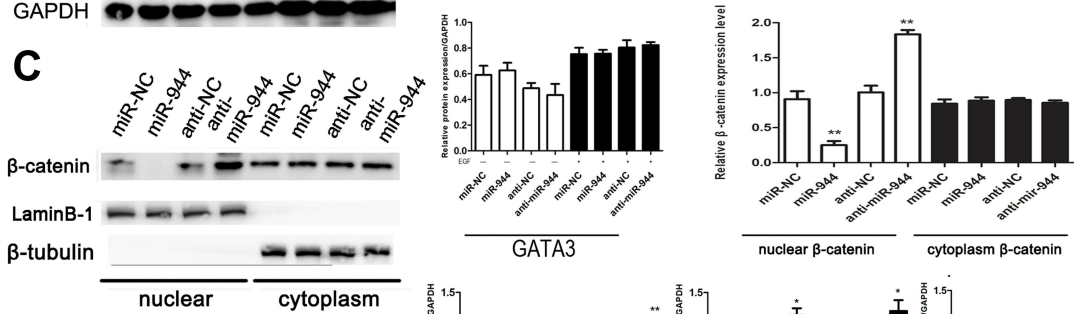

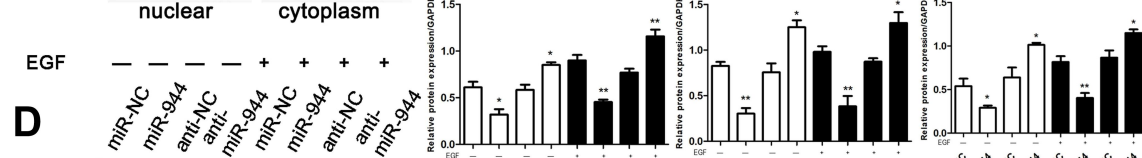

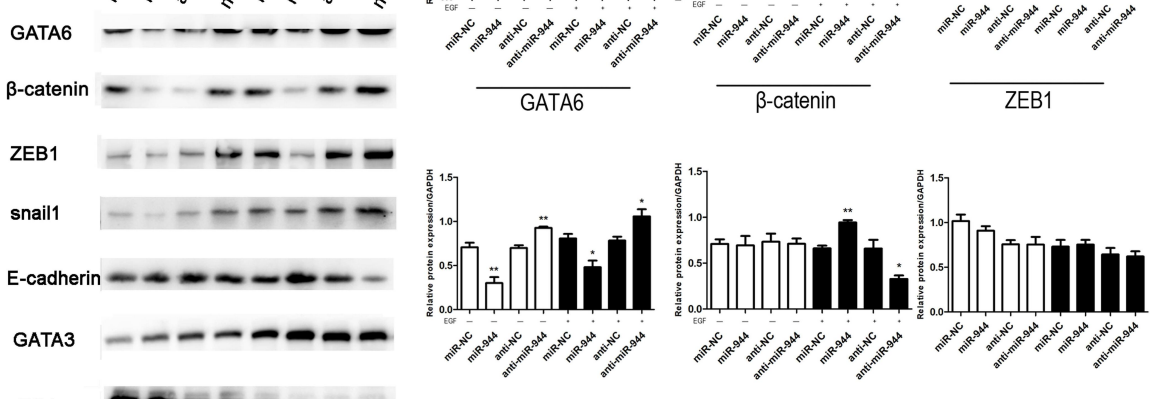

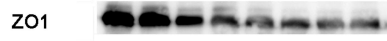
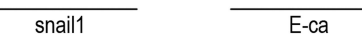

ZO1
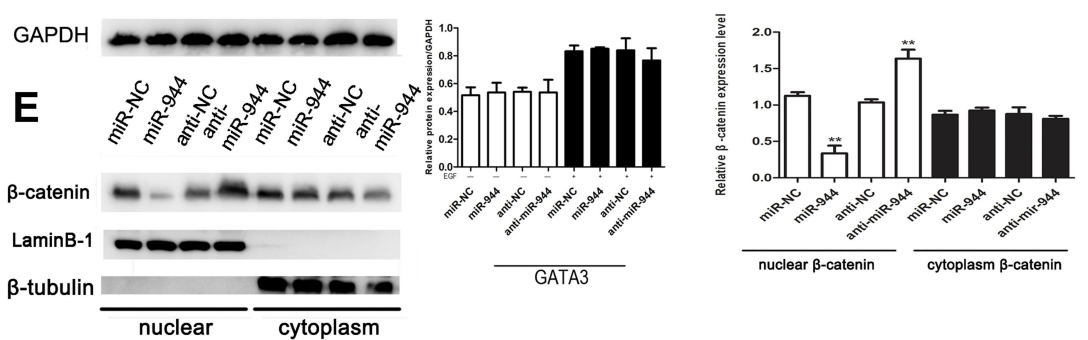

Figure 3 miR-944 inhibits the EGF-induced EMT and wnt- $\beta$-catenin signaling pathway of CRC cells. (A) The KEGG analysis using GSEA comparing genes related to miR-944, GATA6, and miR-944/GATA6 ratio in TCGA. (B) Western blot analysis of GATA6 levels, representing epithelial and wnt- $\beta$-catenin markers in HCTII6. (C) Nuclear $\beta$ catenin change in miR-944, anti-miR-944, and scramble-infected HCTII6. (D) Western blot analysis of GATA6 levels, representing epithelial and wnt- $\beta$-catenin markers in SW480. (E) Nuclear $\beta$-catenin change in miR-944, anti-miR-944, and scramble-infected SW480. White bars indicate target protein expression without EGF treatment, while Black bars indicate target protein expression with EGF treatment. Bars indicate $\pm \mathrm{S} . \mathrm{E}$. ${ }^{\mathrm{P}}<0.05 ; * * \mathrm{P}<0.0$ I compared with control. 

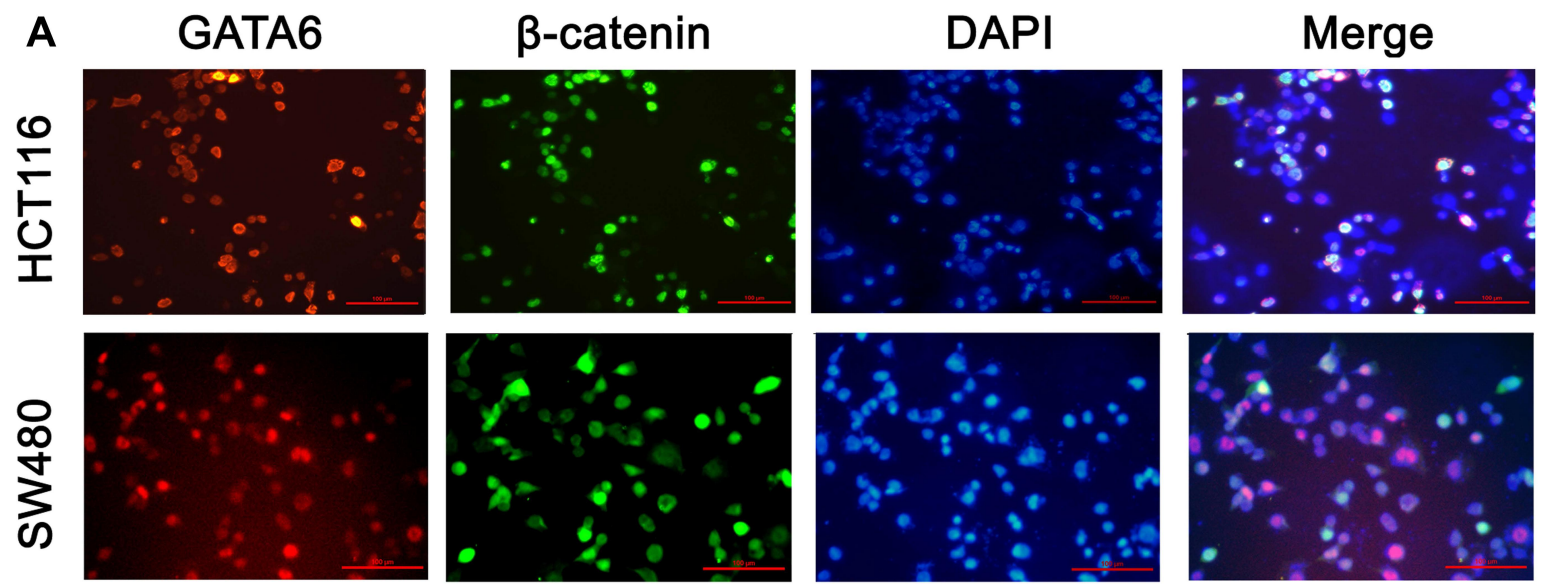

B

GATA6
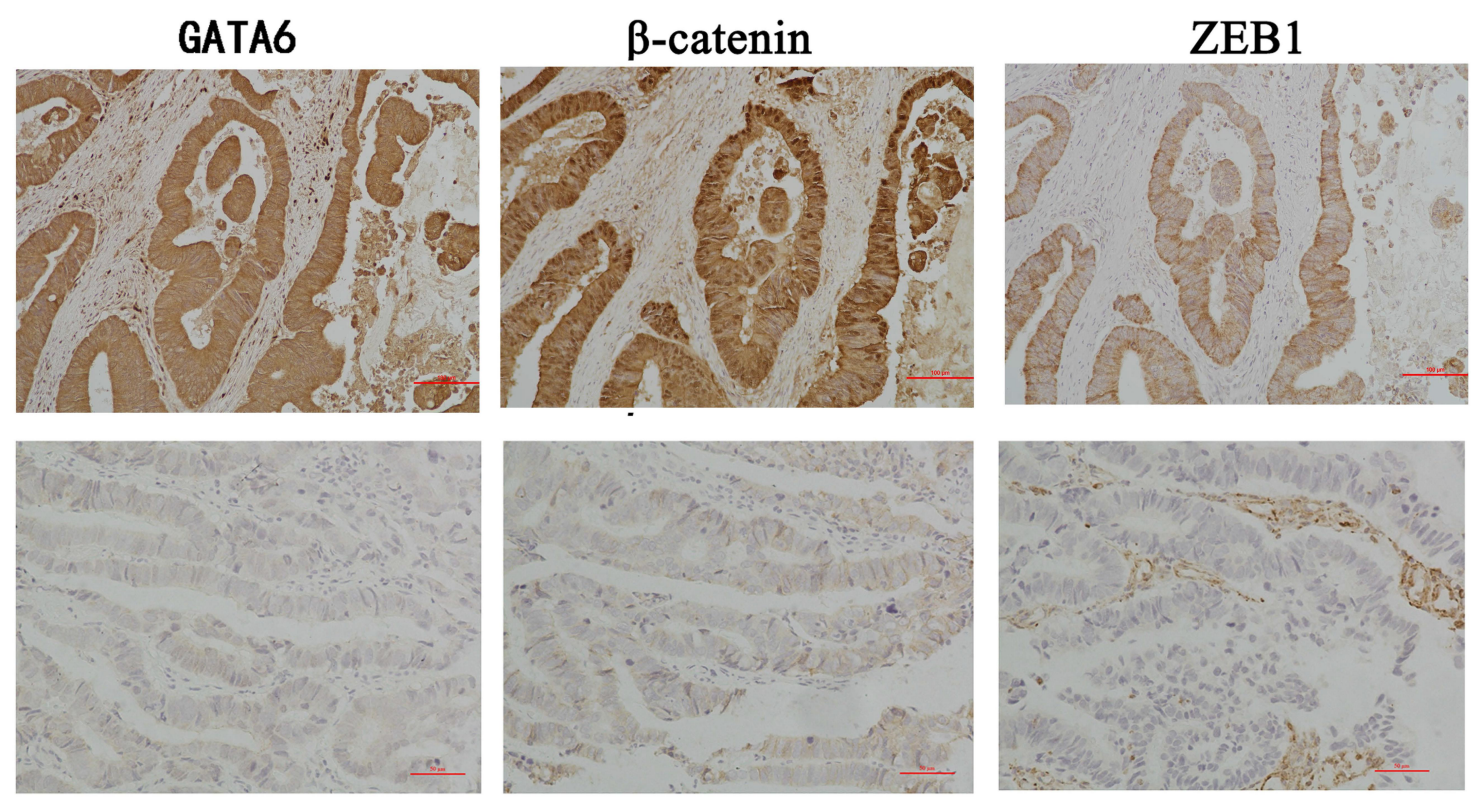

C

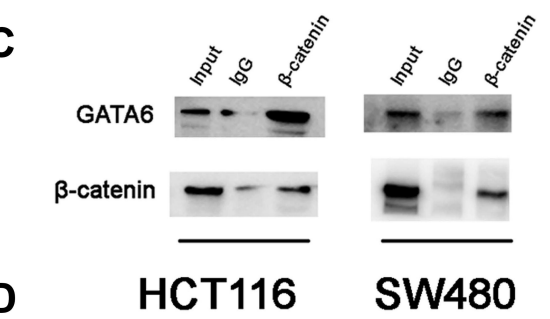

$\mathbf{E}$
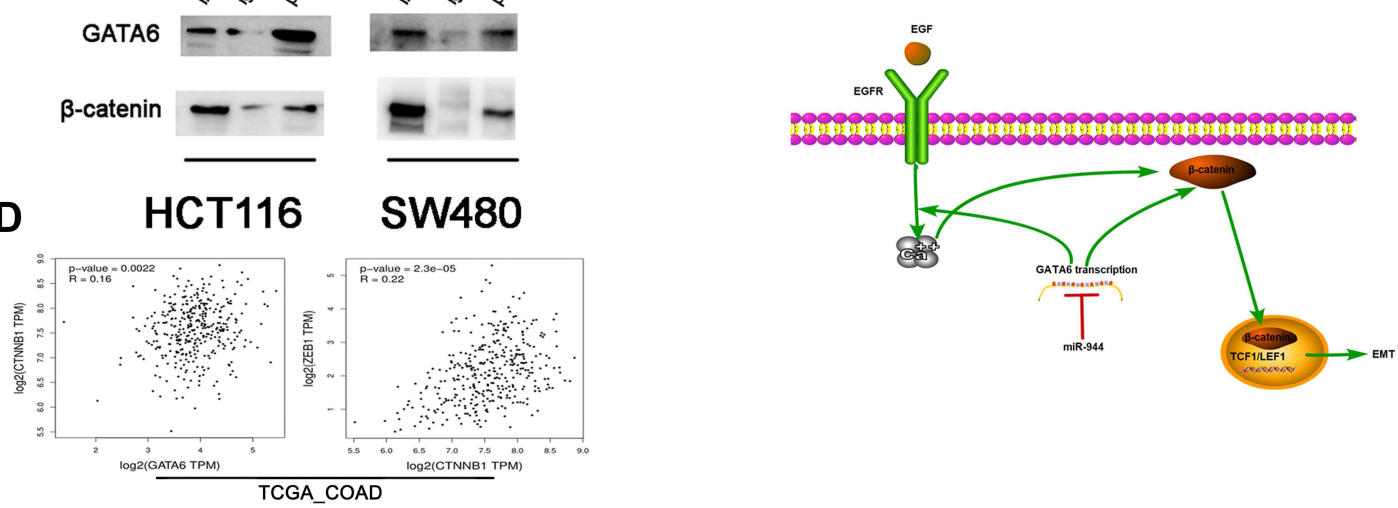

Figure 4 The association between miR-944-GATA6 and wnt- $\beta$-catenin signaling pathway in two CRC cell lines and CRC tissues. (A) The co-staining of GATA6 with $\beta$ catenin in HCTI 16 cells and SW480 using a fluorescence microscope. (B) Co-expression of miR-944 with GATA6, $\beta$-catenin, and ZEBI in low miR-944 tissue and high miR944 tissue using Immunohistochemistry. (C) $\beta$-catenin co-immunoprecipitated with GATA6 in HCT II6 and SW480 cells. The input and IgG lanes were used as the positive and negative controls, respectively. (D) Co-expression analysis showing a positive relationship between GATA6 and $\beta$-catenin, $\beta$-catenin and ZEBI in TCGA_COAD dataset by GEPIA, (E) the diagram illustrating how miR-944 decreased the EMT by inhibiting the GATA6 mediated Wnt/ $\beta$-catenin signaling pathway activity $n=3$. 
Table I Relationship of GATA6 with miR-944, $\beta$-Catenin and ZEBI

\begin{tabular}{|c|c|c|c|c|c|}
\hline & & GA & A6 & & \\
\hline & & Low $^{17}$ & $\mathrm{High}^{33}$ & Pearson & $\mathbf{P}$ \\
\hline miR-944 & $\mathrm{High}^{21}$ & 12 & 9 & 8.642 & 0.003 \\
\hline & Low $^{29}$ & 5 & 24 & & \\
\hline$\beta$-catenin & $\mathrm{High}^{26}$ & 5 & 21 & 5.265 & 0.022 \\
\hline & Low $^{24}$ & 12 & 12 & & \\
\hline ZEBI & $\mathrm{High}^{34}$ & 7 & 27 & 8.517 & 0.004 \\
\hline & Low $^{16}$ & 10 & 6 & & \\
\hline
\end{tabular}

three co-infected groups to further identify the relationship between miR-944 and GATA6 and miR-944 mechanism in CRC. GATA6 silencing reversed the inhibition of HCT116 and SW480 cell invasion and migration caused by the miR-944 inhibitor (Figure 5). We also found that GATA6 could reverse GATA6, $\beta$-catenin, and ZEB1 expressions induced by miR-944 inhibitor in Two CRC cells (Figure 6).

\section{miR-944 is Associated with Poor Survival and miR-944/GATA6 Ratio is a Prognostic CRC Marker}

We used the chi-square test to analyze the relationship between miR-944 expression and clinical parameters in $140 \mathrm{CRC}$ patients. We found that miR-944 is associated with the TNM stage, Lymph node status, and liver metastasis (Table 2). CRC patients were further divided into two groups according to median miR-944 expression level. Kaplan-Meier survival analysis showed that highly expressed miR-944 in CRC patients had a significantly higher overall survival (Figure 7A). We analyzed the relationship between miR-944 expression and clinical parameters in the TCGA dataset and found that miR-944 is negatively associated with the TNM stage, consistent with our results (Figure 7B).

We further evaluated the combination of miR-944 and GATA6 as a potential CRC prognostic biomarker. We integrated the two markers in a ratio (miR-944/GATA6 ratio) in the TCGA dataset and found that high ratio patients had an early TNM stage and high survival using the $\mathrm{R}$ program (4.0.2) (Figure 7C and D). Besides, Univariate and multivariate Cox regression analysis results showed that low miR-944/GATA6 ratio independently causes poor prognosis (Figure 7E and F).

\section{Discussion}

EMT (the transformation from benign to invasive carcinoma) are significantly associated with cancer metastasis. However, the EMT process is complex since several genes and signaling pathways are involved in the progress. While several studies have focused on EMT control at molecular levels, ${ }^{24,25}$ we found that miR-944 downregulation is associated with EMT-related biological processes in CRC (cell adhesion, migration, and invasion). No study has investigated the relationship between miR-944 and EMT and our study provides new information on the EMT mechanism in CRC.

Previous studies have shown that miR-944 suppresses tumors. Flores-Pérez et al $^{26}$ first reported that miR-944 influences breast cancer cell migration by targeting SIAH1 and PTP4A1. Liu et $\mathrm{al}^{27}$ found that miR-944 as a potential miRNA driver inhibits cell growth in non-small cell lung cancer by targeting EPH7A. While miR-944 has been reported to be oncogenic in cervical cancer, ${ }^{28}$ subsequent studies have also revealed that it inhibits gastric cancer metastasis by preventing the epithelial-mesenchymal transition via MACC1/Met/AKT signaling. ${ }^{29} \mathrm{We}$ found that miR944 was negatively associated with CRC patients survival, inhibited CRC EMT phenotype and influenced EMT related protein. Bioinformatics analysis are often used to identify experiments' results in various cancers. ${ }^{30,31}$ Meanwhile, our experiments' results were consistent with the bioinformatics analysis results.

GATA6, a transcription factor gene that is almost amplified or overexpressed in various cancers, is essential in tumor occurrence progress and development. ${ }^{32,33}$ GATA 6 is involved in the mesoderm and endoderm-derived cell differentiation, including Heart, lungs, and gastrointestinal tract. ${ }^{7}$ However, the GATA6 mechanism is still unknown. GATA6 overexpression in breast cancer increases 
A anti-NC+siRNA-NC anti-miR-944+siRNA-NC anti-miR-944+GATA6siRNA
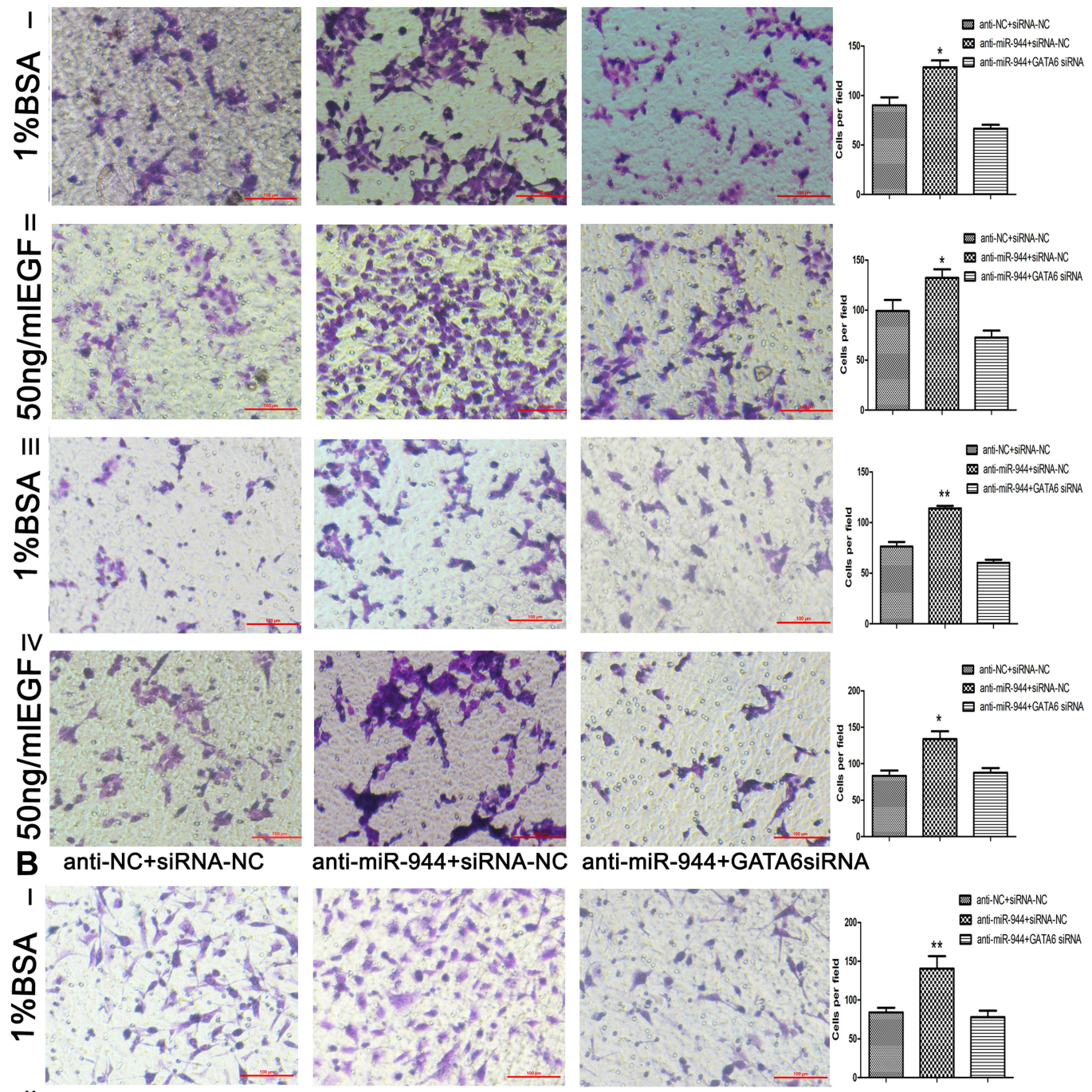

anti-miR-944+siRNA-NC anti-miR-944+GATA6siRNA
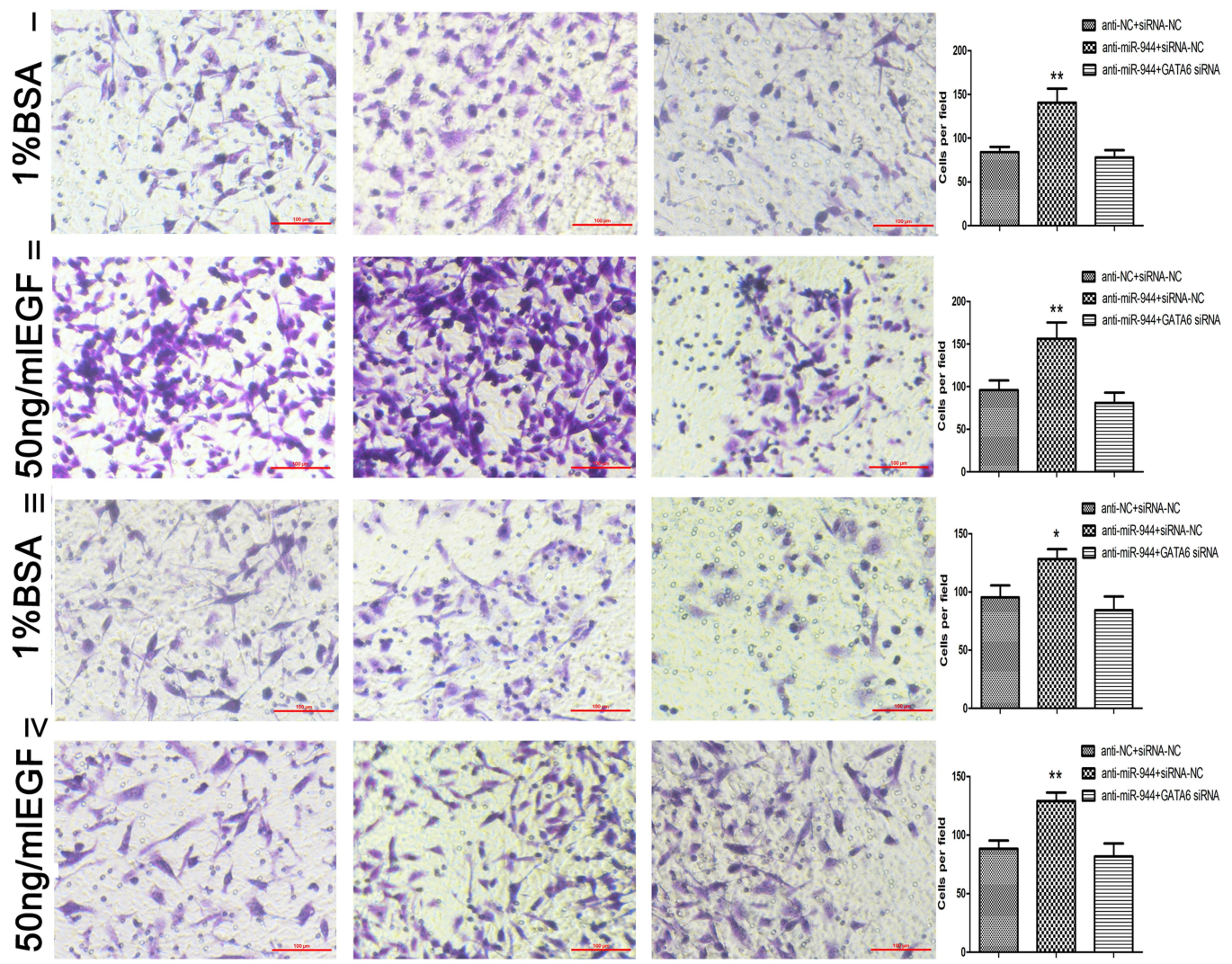

Figure 5 Cell invasion and migration in rescue experiment. GATA6 knockdown reversed cell migration and invasion functions caused by the silencing miR-944 with or without EGF (50 ng/mL) treatment. (A) Cell migration and invasion assays in Human colon cancer cells- II6 (HCTII6) cells, and (B) Cell migration and invasion assays in SW480 cells, $\mathrm{n}=3, * \mathrm{P}<0.05$ and $* * \mathrm{P}<0.01$ using $t$-test. 


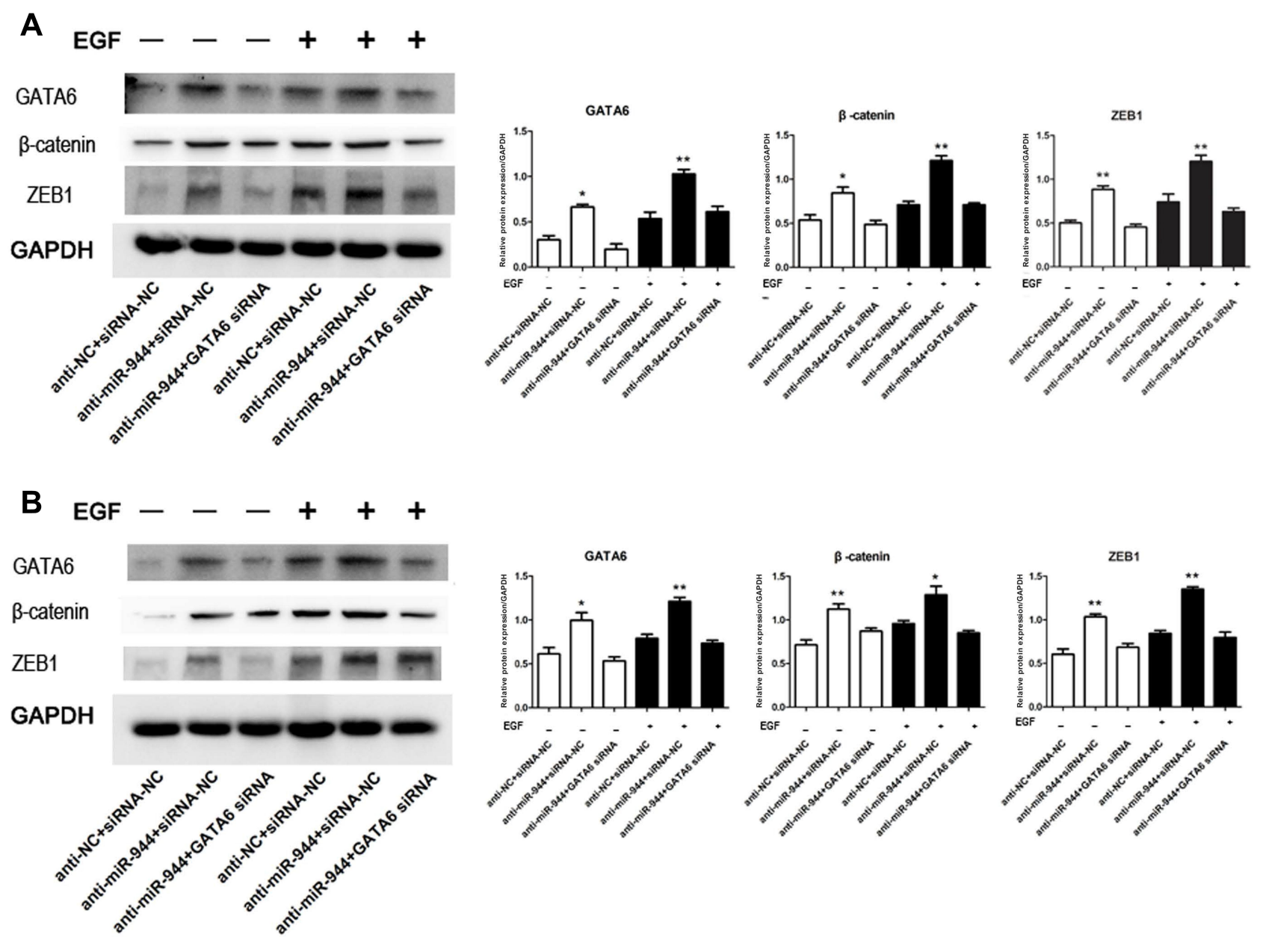

Figure 6 GATA6, $\beta$-catenin, and ZEBI protein changes in rescue experiment. Knockdown reversed the increased GATA6, $\beta$-catenin, and ZEBI expression levels induced by the miR-944 inhibitor with or without EGF (50 ng/mL) treatment. (A) GATA6 antisense experiments in Human colon cancer cells-II6 (HCTII6) cells, and (B) GATA6 antisense experiments in SW480 cells, $\mathrm{n}=3$, $* \mathrm{P}<0.05$ and $* * \mathrm{P}<0.01$ using $t$-test.

epithelial-mesenchymal transition via slug expression upregulation. ${ }^{34}$ Some studies have also indicated that ectopic expressing microRNAs influence GATA6 expression. miR-196b negatively regulates GATA6 expression in colon cancer and miR-124 induces cell invasion and metastasis by directly targeting GATA6 in cholangiocarcinoma. ${ }^{35,36}$ We also identified that miR-944 can suppress GATA6 expression and GATA6 inhibition could reverse the effect on EMT phenotype and related protein induced by anti-miR-944 in CRC cells.

Ectopic Wnt activation is common in human cancers, especially in CRC. ${ }^{37} \mathrm{Wnt}$ signaling plays a critical role in development processes, such as influencing stem cell proliferation and differentiation. ${ }^{38}$ Aberrant activation of canonical Wnt signaling results in $\beta$-catenin nuclear translocation found in the dedifferentiated mesenchyme-like tumor cells undergoing an active EMT associated with E-cadherin downregulation. ${ }^{39}$ It has also been reported that canonical Wnt signaling activation, including TWiST1, ZEB1, and MMP9, amplifies or overexpresses a set of EMT activators. ${ }^{40}$ Conversely, DKK1, a wnt signaling protein inhibitor, suppresses CRC cell malignant biological behaviors via EMT program inhibition. ${ }^{41}$ While Transcription factor (GATA6) has been reported to bind to $\operatorname{lgr} 5$ promoter regulates LGR5 expression in colorectal tumorigenesis which is downstream of the Wnt- $\beta$-catenin signaling pathway. ${ }^{42}$ The Western Blot and co-expression IHC experiment also indicated that GATA6 is associated with $\beta$-catenin and could prompt $\beta$-catenin translocation in the nucleus. We hypothesized that the GATA6 expression decrease induced by miR944 suppresses the EMT process in CRC by mediating the wnt- $\beta$-catenin signaling pathway. 
Table 2 Association of miR-944 Expression Levels with Clinical Data

\begin{tabular}{|c|c|c|c|c|}
\hline \multirow[t]{2}{*}{ Parameters } & \multirow[t]{2}{*}{ No. of Patients } & \multicolumn{2}{|c|}{ Expression of miR-944 } & \multirow[t]{2}{*}{$P$ value } \\
\hline & & Low & High & \\
\hline Age (years) & & & & 0.36 \\
\hline$<60$ & 103 & 42 & 61 & \\
\hline$\geq 60$ & 37 & 17 & 20 & \\
\hline Gender & & & & 0.4 \\
\hline Male & 67 & 27 & 40 & \\
\hline Female & 73 & 32 & 41 & \\
\hline Size (maximal diameter) & & & & 0.07 \\
\hline$\geq 5 \mathrm{~cm}$ & 49 & 16 & 33 & \\
\hline$<5 \mathrm{~cm}$ & 91 & 43 & 48 & \\
\hline Differentiation & & & & 0.17 \\
\hline Well, Moderate & 120 & 53 & 67 & \\
\hline Poor & 20 & 6 & 14 & \\
\hline TNM stage & & & & 0.02 \\
\hline I+II & 86 & 30 & 56 & \\
\hline III+IV & 54 & 29 & 25 & \\
\hline Tumor invasion & & & & 0.42 \\
\hline $\mathrm{TI}+\mathrm{T} 2+\mathrm{T} 3$ & 102 & 42 & 60 & \\
\hline $\mathrm{T} 4$ & 38 & 17 & 21 & \\
\hline Lymph node status & & & & 0.04 \\
\hline Positive & 89 & 32 & 57 & \\
\hline Negative & 51 & 27 & 24 & \\
\hline Metastasis & & & & 0.03 \\
\hline Mo & 127 & 49 & 78 & \\
\hline MI & 13 & 9 & 4 & \\
\hline
\end{tabular}

Furthermore, miR-944 can regulate the EMT process by mediating $\mathrm{Ca} 2+$. The KEGG analysis results showed that miR-944 expression is significantly related to the Calcium signaling pathway. Increasing piece of evidence have shown that intracellular calcium alteration in various cancer cells affects tumor progression, migration, invasion, and metastasis. ${ }^{43,44}$ Intracellular calcium and intracellular calcium increase in breast cancer abrogate EMT phenotype, resulting in $\beta$-catenin nuclear translocation, and this could be the potential canonical Wnt/ $\beta$-catenin mechanism. ${ }^{23}$ We found that miR-944 mimics inhibited $\beta$ catenin expression in the nucleus. It has also been confirmed that GATA6 as a transcription factor can bind to the calreticulin (CRT) promoter in mice and humans via reporter gene and ChiP analyses. ${ }^{45}$ Our previous study also found that CRT is positively related to miR-944 and
GATA6. CRT regulates the increase of intracellular calcium, Integrin $\beta 1$, Fibronectin, and c-Myc expressions induced by EGF in MDCK cells. ${ }^{17}$ CRT also influences calcium release and influx in integrin-mediated $\mathrm{Ca} 2+$ signaling pathway. ${ }^{46,47}$ Therefore, miR-944-GATA6 regulates CRC EMT phenotype by mediating intracellular calcium.

In conclusion, miR-944-GATA6 suppresses EGFinduced EMT in CRC cells via the wnt/ $\beta$-catenin signaling pathway which could also be regulated via CRT-mediated change of intracellular calcium. Importantly, the miR-944/GATA6 ratio is a novel biomarker of survival and treatment outcome in CRC patients. However, the relationship between intracellular calcium and EMT, and miR-944-GATA6 mechanism are still unknown and will be further investigated in our future study. 
A miR-944 expression $(\mathrm{p}=0.045)$

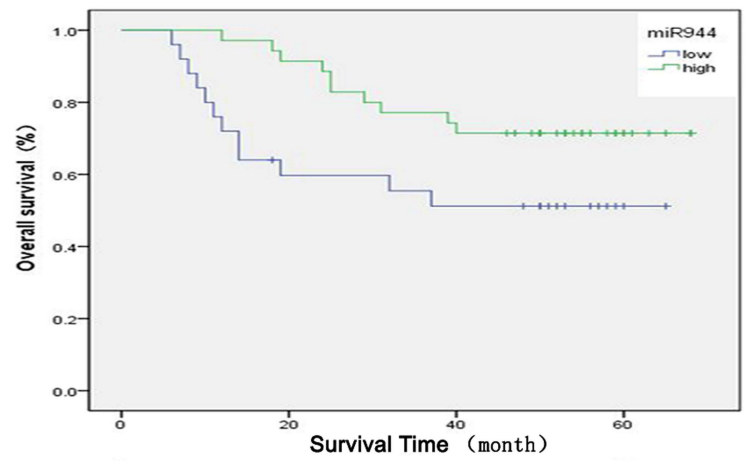

C

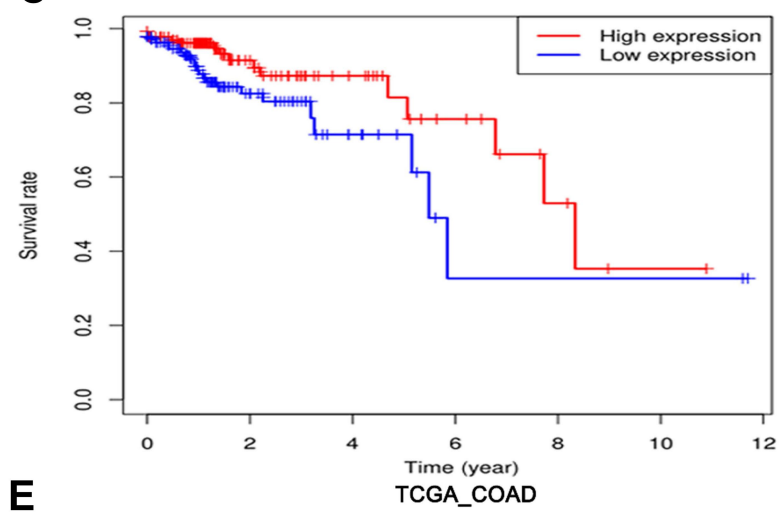

$\mathbf{E}$

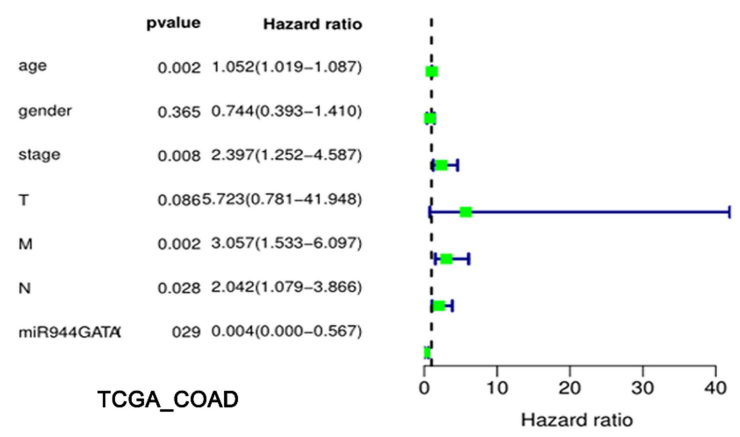

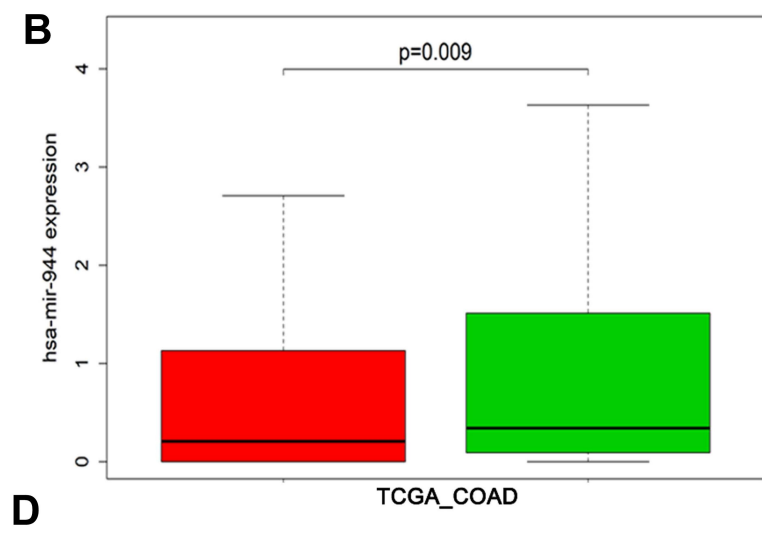
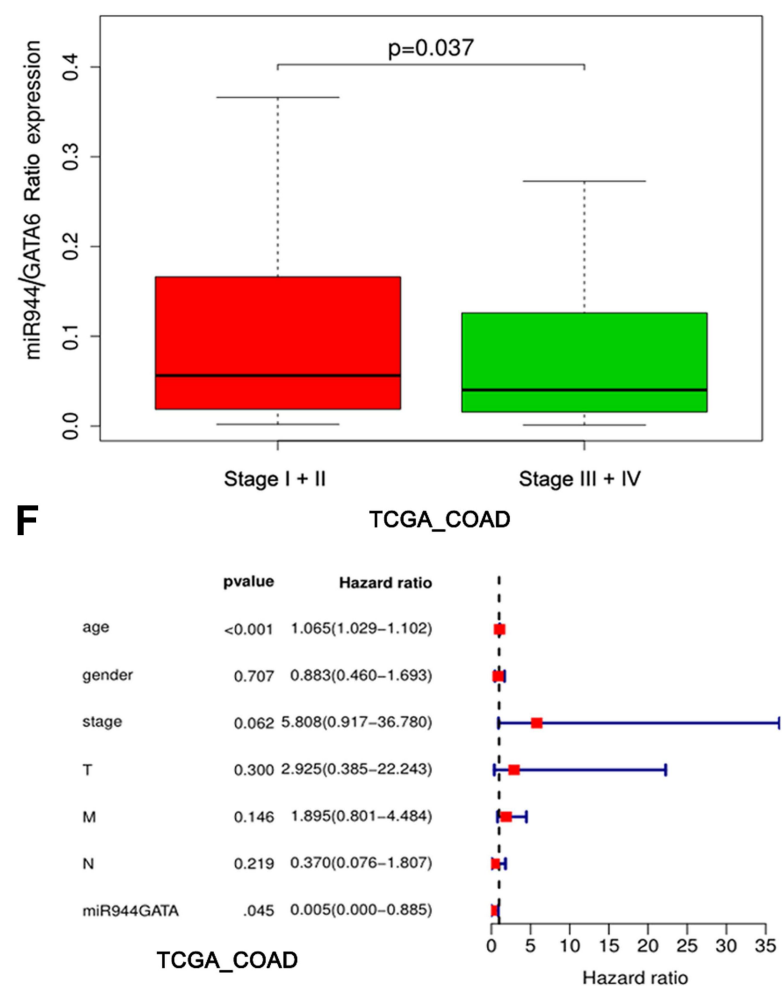

Figure 7 Identification of the miR-944 and miR-944/GATA6 ratio as a CRC prognosis marker. (A) High and low miR-944 expressions plotted against overall survival time in $60 \mathrm{CRC}$ patients. (B) Chi-square analysis of the relationship between the miR-944 and clinical stage in TCGA data. (C) High and low miR-944/GATA6 expression ratio plotted against overall survival time in TCGA. (D) Chi-square analysis of the relationship between the miR-944/GATA6 ratio and clinical stage in TCGA data. (E) Univariate Cox regression analysis of the relationship between the miR-944/GATA6 ratio and prognosis in TCGA. (F) multivariate Cox regression analysis of the relationship between the miR-944/GATA6 ratio and prognosis in TCGA.

\section{Ethics Approval and Consent}

The Ethics Committee of China Medical University authorized all experiments in this study. Written informed consent was obtained from patients.

\section{Consent for Publication}

Not applicable.

\section{Author Contributions}

All authors made substantial contributions to conception and design, acquisition of data, or analysis and interpretation of data; took part in drafting the article or revising it critically for important intellectual content; agreed to submit to the current journal; gave final approval of the version to be published; and agree to be accountable for all aspects of the work. 


\section{Funding}

This study was supported by Scientific Research of Special transformation project of medical science and technology achievements of Liaoning Province, China (Liao Ke Fa, No. 2019-24).

\section{Disclosure}

The authors declare that they have no conflicts of interest for this work.

\section{References}

1. Miller KD, Nogueira L, Mariotto AB, et al. Cancer treatment and survivorship statistics, 2019. CA Cancer J Clin. 2019;69(5).

2. Chen W, Zheng R, Baade PD, et al. Cancer statistics in China, 2015. CA Cancer J Clin. 2016;66(2). doi:10.3322/caac.21338.

3. Siegel RL, Miller KD, Jemal A. Cancer statistics, 2018. CA Cancer J Clin. 2018;68(1):7-30. doi:10.3322/caac.21442

4. Cao H, Xu E, Liu H, et al. Epithelial-mesenchymal transition in colorectal cancer metastasis: a system review. Pathol Res Pract. 2015. doi:10.1016/j.prp.2015.05.010

5. Bocca C, Bozzo F, Cannito S, et al. Celecoxib inactivates epithelial-mesenchymal transition stimulated by hypoxia and/or epidermal growth factor in colon cancer cells. Mol Carcinog. 2012;51 (10):783-795. doi:10.1002/mc.20846

6. Reka AK, Kuick R, Kurapati H, et al. Identifying inhibitors of epithelial-mesenchymal transition by connectivity map-based systems approach. J Thorac Oncol. 2011;6:1784-1792. doi:10.1097/ JTO.0b013e31822adfb0

7. Rojas A, Fernandez MC, Soria B, Martín F, Rojas A. GATA4 and GATA6 control mouse pancreas organogenesis. J Clin Invest. 2012;122(10):3504. doi:10.1172/JCI63240

8. Chen Y, Yang L, Cui T, et al. HOPX is methylated and exerts tumour-suppressive function through Ras-induced senescence in human lung cancer. J Pathol. 2015.

9. Tian F, Li D, Chen J, et al. Aberrant expression of GATA binding protein 6 correlates with poor prognosis and promotes metastasis in cholangiocarcinoma. Eur $J$ Cancer. 2013;49(7):1771-1780. doi:10.1016/j.ejca.2012.12.015

10. Lv L, Wang X, Ma T. microRNA-944 inhibits the malignancy of hepatocellular carcinoma by directly targeting IGF-1R and deactivating the PI3K/Akt signaling pathway. Cancer Manag Res. 2019;11:2531-2543. doi:10.2147/CMAR.S199818

11. Kim YJ, Lee JH, Jin S, et al. Primate-specific miR-944 activates p53-dependent tumor suppression in human colorectal cancers. Cancer Lett. 2018.

12. Tang JT, Zhao J, Sheng W, et al. Ectopic expression of miR-944 impairs colorectal cancer cell proliferation and invasion by targeting GATA binding protein 6. J Cell Mol Med. 2019;23:3483-3494. doi: $10.1111 /$ jcmm.14245

13. Tang Z, Li C, Kang B, et al. GEPIA: a web server for cancer and normal gene expression profiling and interactive analyses. Nucleic Acids Res. 2017;45:W98-W102. doi:10.1093/nar/gkx247

14. Sheng W, Dong M, Chen C, et al. Cooperation of Musashi-2, Numb, MDM2, and P53 in drug resistance and malignant biology of pancreatic cancer. FASEB J off Publ Fed Am Soc Exp Biol. 2017;31 (6):2429. doi:10.1096/fj.201601240R

15. Sheng W, Shi X, Lin Y, et al. Musashi2 promotes EGF-induced EMT in pancreatic cancer via ZEB1-ERK/MAPK signaling. J Exp Clin Cancer Res. 2020;39(1).
16. Sheng W, Chen C, Dong $M$, et al. Calreticulin promotes EGF-induced EMT in pancreatic cancer cells via Integrin/ EGFR-ERK/MAPK signaling pathway. Cell Death Dis. 2017;8(10): e3147. doi:10.1038/cddis.2017.547

17. Basu S, Cheriyamundath S, Ben-Ze'Ev A. Cell-cell adhesion: linking $W n t / \beta$-catenin signaling with partial EMT and stemness traits in tumorigenesis. F1000 Res. 2018;7:1488. doi:10.12688/ f1000research.15782.1

18. Hwang JTK, Kelly GM. GATA6 and FOXA2 regulate Wnt6 expression during extraembryonic endoderm formation. Stem Cells Dev. 2012;21(17):3220. doi:10.1089/scd.2011.0492

19. Morciano G, Marchi S, Morganti C, et al. Role of mitochondria-associated ER membranes in calcium regulation in cancer-specific settings. Neoplasia. 2018;20(5):510. doi:10.1016/j. neo.2018.03.005

20. Fourbon Y, Guéguinou M, Félix R, et al. Ca2+ protein alpha 1D of $\mathrm{CaV} 1.3$ regulates intracellular calcium concentration and migration of colon cancer cells through a non-canonical activity. Sci Rep. 2017;7(1):14199.

21. Chong-Yu Z, Xin-Yuan S, Jian-Ming O, et al. Diethyl citrate and sodium citrate reduce the cytotoxic effects of nanosized hydroxyapatite crystals on mouse vascular smooth muscle cells. Int J Nanomed. 2017;12:8511-8525. doi:10.2147/IJN.S145386

22. Liu L, Yang M, Wang N, et al. New insights of subfertility among transplanted women: immunosuppressive drug FK506 leads to calcium leak and oocyte activation before fertilization. J Cell Biochem. 2017.

23. Davis FM, Azimi I, Faville RA, et al. Induction of epithelialmesenchymal transition (EMT) in breast cancer cells is calcium signal dependent. Oncogene Basingstoke. 2014;33:2307-2316. doi:10.1038/onc.2013.187

24. Yang Z, Liu S, Zhu M, et al. PS341 inhibits hepatocellular and colorectal cancer cells through the FOXO3/CTNNB1 signaling pathway. Sci Rep. 2016;6:22090.

25. Rokavec M, Öner MG, Li H, et al. IL-6R/STAT3/miR-34a feedback loop promotes EMT-mediated colorectal cancer invasion and metastasis. J Clin Invest. 2014;124(4):1853-1867. doi:10.1172/JCI73531

26. Flores-Pérez A, Marchat LA, Rodríguez-Cuevas S, et al. Suppression of cell migration is promoted by miR-944 through targeting of SIAH1 and PTP4A1 in breast cancer cells. BMC Cancer. 2016;16 (1):379. doi:10.1186/s12885-016-2470-3

27. Liu M, Zhou K, Cao Y. MicroRNA-944 affects cell growth by targeting EPHA7 in non-small cell lung cancer. Int $J$ Mol Sci. 2016;17(10). doi:10.3390/ijms17101493

28. Liu SS, Chan KKL, Chu DKH, et al. Oncogenic microRNA signature for early diagnosis of cervical intraepithelial neoplasia and cancer. Mol Oncol. 2018. doi:10.1002/1878-0261.12383

29. Pan T, Chen W, Yuan X, et al. miR-944 inhibits metastasis of gastric cancer by preventing the epithelial-mesenchymal transition via MACC1/Met/AKT signaling. FEBS Open Bio. 2017;7(7):905-914. doi:10.1002/2211-5463.12215

30. Rahman MR, Islam T, Gov E, et al. Identification of prognostic biomarker signatures and candidate drugs in colorectal cancer: insights from systems biology analysis. Medicina. 2019;55(1):20. doi:10.3390/medicina55010020

31. Islam T, Rahman MR, Shuvo MAH, et al. Drug repositioning and biomarkers in low-grade glioma via bioinformatics approach. Inf Med Unlocked. 2019. doi:10.1016/j.imu.2019.100250

32. Nakajima N, Yoshizawa A, Nakajima T, et al. GATA6-positive lung adenocarcinomas are associated with invasive mucinous adenocarcinoma morphology, hepatocyte nuclear factor $4 \alpha$ expression, and KRAS mutations. Histopathology. 2018. doi:10.1111/his.13500 
33. Chia NY, Deng N, Das K, et al. Regulatory crosstalk between lineage-survival oncogenes KLF5, GATA4 and GATA6 cooperatively promotes gastric cancer development. Gut. 2015;64(5):707-719. doi:10.1136/gutjnl-2013-306596

34. Song Y, Tian T, Fu X, et al. GATA6 is overexpressed in breast cancer and promotes breast cancer cell epithelial mesenchymal transition by upregulating slug expression. Exp Mol Pathol. 2015;99(3):617-627. doi:10.1016/j.yexmp.2015.10.005

35. Fantini S, Salsi V, Reggiani L, et al. The miR-196b miRNA inhibits the GATA6 intestinal transcription factor and is upregulated in colon cancer patients. Oncotarget. 2017;8(3):4747-4759. doi:10.18632/ oncotarget. 13580

36. Tian F, Chen J, Zheng S, et al. miR-124 targets GATA6 to suppress cholangiocarcinoma cell invasion and metastasis. BMC Cancer. 2017;17(1):175. doi:10.1186/s12885-017-3166-z

37. Novellasdemunt L, Antas P. Li V S W. Targeting Wnt signaling in colorectal cancer. Ajp Cell Physiol. 2015;ajpcell.00117.2015. doi:10.1152/ajpcell.00117.2015

38. van der Flier LG, Clevers H. Stem cells, self-renewal, and differentiation in the intestinal epithelium. Annu Rev Physiol. 2009;71:241-260. doi:10.1146/annurev.physiol.010908.163145

39. Thiery JP. Epithelial-mesenchymal transitions in tumour progression. Nat Rev Cancer. 2002;2(6):442-454. doi:10.1038/nrc822

40. De Lau W, Peng WC, Gros P, et al. The R-spondin/Lgr5/Rnf43 module: regulator of Wnt signal strength. Genes Dev. 2014;28 (4):305-316. doi:10.1101/gad.235473.113
41. Qi L, Sun B, Liu Z, et al. Dickkopf-1 inhibits epithelial-mesenchymal transition of colon cancer cells and contributes to colon cancer suppression. Cancer Sci. 2012;103(4):828-835. doi:10.1111/j.13497006.2012.02222.x

42. Yang B, Mao L, Li Y, et al. $\beta$-catenin, leucine-rich repeat-containing $\mathrm{G}$ protein-coupled receptor 5 and GATA-binding factor 6 are associated with the normal mucosa-adenoma-adenocarcinoma sequence of colorectal tumorigenesis. Oncol Lett. 2017. doi:10.3892/ ol.2017.7566

43. Rønnov-Jessen L, Bissell MJ. Breast cancer by proxy: can the microenvironment be both the cause and consequence? Trends Mol Med. 2009;15(1):5-13. doi:10.1016/j.molmed.2008.11.001

44. Monteith GR, Davis FM, Roberts-Thomson SJ. Calcium channels and pumps in cancer: changes and consequences. J Biol Chem. 2012;287(38):31666-31673. doi:10.1074/jbc.R112.343061

45. Qiu Y, Michalak M. Transcriptional control of the calreticulin gene in health and disease. Int J Biochem Cell Biol. 2009;41(3):531-538. doi:10.1016/j.biocel.2008.06.020

46. Ihara Y, Inai Y, Ikezaki M, et al. Alteration of integrin-dependent adhesion and signaling in EMT-like MDCK cells established through overexpression of calreticulin. J Cell Biochem. 2011;112:2518-2528. doi:10.1002/jcb.23176

47. Kwon MS, Park CS, Choi K, et al. Calreticulin couples calcium release and calcium influx in integrin-mediated calcium signaling. Mol Biol Cell. 2000;11(4):1433-1443. doi:10.1091/mbc.11.4.1433

\section{Publish your work in this journal}

OncoTargets and Therapy is an international, peer-reviewed, open access journal focusing on the pathological basis of all cancers, potential targets for therapy and treatment protocols employed to improve the management of cancer patients. The journal also focuses on the impact of management programs and new therapeutic agents and protocols on patient perspectives such as quality of life, adherence and satisfaction. The manuscript management system is completely online and includes a very quick and fair peer-review system, which is all easy to use. Visit http://www.dovepress.com/ testimonials.php to read real quotes from published authors. 